\title{
Food Engineering Reviews Special Issue Based on the 2019 IFT-NPD/ EFFoST Nonthermal Processing of Food Workshop at Tecnológico de Monterrey, Mexico
}

\author{
J. Antonio Torres ${ }^{1}$. Jorge Welti-Chanes ${ }^{1}$ - Gustavo V. Barbosa-Cánovas ${ }^{2}$ \\ Accepted: 16 August 2021 / Published online: 1 September 2021 \\ (c) The Author(s), under exclusive licence to Springer Science+Business Media, LLC, part of Springer Nature 2021
}

This Special Issue includes peer-reviewed articles based on presentations delivered during the 2019 Nonthermal Processing Workshop (NPW) held on November 3-6, 2019, at Tecnológico de Monterrey, Nuevo León, Mexico. This institution was selected as the site for the workshop because of the number of faculty, students, postdocs, and technician working on advanced food processing technologies and allied disciplines, specifically biotechnology, as well as for its excellent facilities, which include a state-of-the-art food processing pilot plant, specialized laboratories, and modern conference rooms. The selection was made upon recommendation by the IFT-NPD/EFFoST Joint Workshop Committee.

The Guest Editors of this publication are J. Antonio Torres, Jorge Welti-Chanes, and Gustavo V. Barbosa-Cánovas. They took the responsibility to assess the suitability of the manuscripts for the journal and decide whether to send them for review or reject them. Those manuscripts that went for review received feedback from at least two reviewers plus one of the editors. The Guest Editors were very rigorous to make sure only excellent quality articles would be included in this Special Issue which has 10 reviews and 13 research articles. In general, this journal only publishes review articles, but an exception was made to feature some relevant research work based on presentations at the NPW. The Guest Editors are very thankful to the reviewers for contributing expertise and valuable time to ensure the quality of the articles. The publisher, Springer Nature, was very helpful to facilitate the production of this Special Issue. This is very much appreciated as well.

\footnotetext{
Jorge Welti-Chanes

jwelti@tec.mx

Tecnológico de Monterrey, Monterrey, Mexico

2 Washington State University, Pullman, USA
}

\section{Highlights of the 2019 IFT NPD/EFFoST International Nonthermal Processing of Food Workshop}

The Nonthermal Processing Division of the Institute of Food Technologists (IFT-NPD) and the European Federation of Food Science and Technology (EFFoST) have been organizing annual workshops and short courses on nonthermal processing technologies to process foods over the last two decades. Earlier workshops and short courses alternated between the USA and European countries, and lately, because of the growing worldwide interest in nonthermal processing technologies, several countries outside the USA and Europe have been organizing and hosting these workshops.

The 2019 Nonthermal Processing Workshop and Short Courses at Tecnológico de Monterrey had 218 attendees from twenty countries. The following three short courses were offered before or after the NPW, "Status \& Applications of Nonthermal Technologies" (111 attendees, 18 instructors), "Sensory Evaluation of Nonthermally Processed Food Products" (30 attendees, 4 instructors), and "Nonthermal Food Process Design Tools" (35 attendees, 4 instructors).

The workshop included invited lectures, contributed oral and poster presentations, and industrial roundtables. The meeting covered numerous food and biotechnology updates in advanced processing technologies including, among others, high-pressure processing (HPP), pulsed electric fields (PEF), light-based technologies, ohmic heating, microwave pasteurization/sterilization, and membrane processing. The oral presentations were grouped into four sessions covering fundamentals and applications of advanced processing technologies, whereas the posters were grouped into two sessions which included 3-min oral presentations. In addition, there were two round tables, "Nonthermal Food Processing Industrial Research Needs" and "Commercialization 
and Regulation of Nonthermally Processed Products" with the participation of six international panelists with broad experience on novel technologies to process foods and other biomaterials.

The workshop and the short courses were organized by Tecnológico de Monterrey with Jorge Welti-Chanes as chair and $\mathrm{J}$. Antonio Torres as co-chair, with the collaboration of all members of the IFT-NPD / EFFoST Joint Workshop Committee. This partnership resulted in a very successful meeting not only for the high scientific and technical quality but for the opportunity for networking and socializing. The workshop leaders at Tecnológico de Monterrey appointed a local organizing committee led by Professor Cristina Chuck-Hernández and subcommittees dealing with scientific, marketing, registration, and sponsorship tasks which were led by Zamantha EscobedoAvellaneda, José Rodríguez-Rodríguez, Rosa Rubio-Sandoval, Daniel Guajardo-Flores, Karla Mayolo-Deloisa, Rebeca García-García, María José Escalante-Valdez, and Rosa Selene Espiricueta-Candelaria. The IFT NPD/EFFoST Workshop Committee had the following members: for EFFoST, Olga Martín-Belloso (co-chair), Oliver Schlüter, and Lilia Ahrné, and for IFT, Gustavo V. Barbosa-Cánovas (co-chair), Roman Buckow, and Marcia Walker. We thank also Professor Giovanna Ferrari, organizer of 2018 IFT-EFFoST Nonthermal NPD Workshop, who shared her experience and provided extensive programe details.
During the workshop closing ceremony, Professor Gustavo V. Barbosa-Cánovas received the "2019 IFTEFFoST Nonthermal Processing of Food Lifetime Achievement Award" in recognition of his relevant and continuous contributions to basic research, development, and implementation of a number of nonthermal food processing technologies.

As Guest Editors, we want to acknowledge and give special thanks to the organizing committee, subcommittees, and IFT-NPD/EFFoST Joint Workshop Committee members, as well as to all speakers, poster presenters, and attendees who made this workshop, together with the short courses, a highquality scientific and technological event.

We are convinced that this Food Engineering Reviews Special Issue will be an important addition to the body of knowledge on nonthermal and advanced thermal processing because of the high quality, novelty, and relevance of all the review and research articles included.

Publisher's Note Springer Nature remains neutral with regard to jurisdictional claims in published maps and institutional affiliations. 